\title{
Pseudomonas aeruginosa Mutants Defective in Heptane Oxidation
}

\author{
By L. P. MACHAM* AND M. T. HEYDEMAN \\ Department of Microbiology, University of Reading, Reading $R G$ I $5 A Q$
}

(Received 27 May 1974)

\begin{abstract}
SUMMARY
Fourteen mutants of Pseudomonas aeruginosa ATCC 17423, isolated for their inability to grow rapidly on heptane while still growing normally on heptanoic acid, were all also able to grow on heptanol or heptanal. A study of heptane oxidation in extracts showed differences between the mutants, which were resolved into four groups (A to D). Group A or B alone could not oxidize heptane, but a mixture of the extracts was effective, and either A or B stimulated the slight activity of extracts from group D mutants. Extracts from group $C$ mutants were inactive in virtually all circumstances. The mutants therefore lack, in different ways, one or more of the three components demonstrated to be necessary for heptane oxidation, but no mutant totally lacking rubredoxin was demonstrated.
\end{abstract}

\section{INTRODUCTION}

Alkane oxidation in Pseudomonas aeruginosa (van Eyk \& Bartels, 1970) appears generally similar in mechanism to that in P. oleovorans (Baptist, Gholson \& Coon, 1963; Gholson, Baptist \& Coon, 1963) and $P$. denitrificans (Kusunose et al. 1967). Enzymological investigations have shown a three-component alkane hydroxylase, yielding the corresponding primary alcohol; this is oxidized to the aldehyde and then the acid by dehydrogenases. Mutants of $P$. denitrificans lacking the ability to grow on hexadecane, but stillable to grow in hexadecanoic acid, were isolated by Illarionov (1972). Some of these mutants grew on hexadecanol or hexadecanal, some on hexadecanal but not hexadecanol, and a large number $(50 \%$ of all alkane-defective mutants) on hexadecanol but not hexadecanal. Jenkins, Raboin \& Moran (1972) isolated mutants of Mycobacterium rhodochrous B29 which normally grows on any of several alkanes. Some mutants no longer grew on any alkane tested; some no longer grew on certain alkanes, but could grow on others. One mutant, unable to grow on octane, still possessed octane hydroxylase activity in extracts of organisms grown on other alkanes. This paper describes the $n$-heptane oxidizing system of $P$. aeruginosa ATCC 17423 and the defective systems of mutants derived from this strain.

\section{METHODS}

Organism. Pseudomonas aeruginosa ATCC 17423 was kindly provided by Professor R. Y. Stanier, University of California, Berkeley, U.S.A. Stock cultures were maintained on nutrient agar slopes at room temperature.

Growth of bacteria. Bacteria were grown at $30^{\circ} \mathrm{C}$ in 21 flasks containing $500 \mathrm{ml}$ liquid mineral medium on a rotary shaker. The medium contained: $35 \mathrm{mM}-\mathrm{Na}_{2} \mathrm{HPO}_{4}$; $15 \mathrm{~mm}-$ $\left(\mathrm{NH}_{4}\right)_{2} \mathrm{SO}_{4} ; \quad \mathrm{I} 8 \mu \mathrm{M}-\mathrm{FeSO}_{4} ; \mathrm{I} \cdot 9 \mu \mathrm{M}-\mathrm{ZnSO}_{4} ; 360 \mathrm{nM}-\mathrm{MnSO}_{4} ; 200 \mathrm{nM}-\mathrm{Na}_{2} \mathrm{MoO}_{4} ; \quad$ I $60 \mathrm{nM}-$ $\mathrm{CuSO}_{4} ; \mathrm{I} 60 \mathrm{nM}-\mathrm{CoCl}_{2} ; \mathrm{I} \cdot 6 \mu \mathrm{M}-\mathrm{MgCl}_{2}$; and $260 \mathrm{nM}-\mathrm{CaCl}_{2}$. The last two components were

\footnotetext{
* Present address: Department of Biochemistry, University of Hull, Hull HU6 7 RX.
} 
autoclaved separately and added immediately before inoculation. Heptane $(2 \mathrm{ml})$ was added to some cultures as carbon and energy source and the growing culture was harvested by centrifuging after 24 to $36 \mathrm{~h}$ incubation. Alternatively, cultures were supplied with $10 \mathrm{~mm}$ sodium malonate in the mineral medium. After $16 \mathrm{~h}$ further $10 \mathrm{~mm}$-sodium malonate $(7.5 \mathrm{ml}$ of $10 \%, \mathrm{w} / \mathrm{v}$, solution) was added to the $500 \mathrm{ml}$ culture, with $2 \mathrm{mM}$-diethoxymethane, a gratuitous inducer of the alkane oxidizing system (van Eyk \& Bartels, I968). After a further $6 \mathrm{~h}$ incubation, the bacteria were harvested by centrifuging. This latter method was preferred because extracts were free from the traces of heptanoic acid sometimes present in extracts of heptane-grown organisms.

Mutant isolation. Bacteria taken in the exponential phase of growth from a nutrient broth culture were resuspended at about $5 \times 10^{7}$ organisms $/ \mathrm{ml}$ in $0 . \mathrm{I}$ M-citrate buffer $\mathrm{pH} 6.0$ and then Io $\mu \mathrm{g} N$-methyl- $N^{\prime}$-nitro- $N$-nitrosoguanidine/ml were added. After I 5 min at room temperature, the bacteria were centrifuged, resuspended in nutrient broth and left, unshaken, at $30^{\circ} \mathrm{C}$ for $5 \mathrm{~h}$. The viable count was determined in a small sample and the remainder was stored at $3{ }^{\circ} \mathrm{C}$ for $24 \mathrm{~h}$. It was then diluted in mineral medium to give 1000 organisms $/ \mathrm{ml}$ and $0 . \mathrm{I} \mathrm{ml}$ samples were spread on agar plates containing mineral medium solidified with I.5\% Difco Special Agar-Noble. The plates were incubated at $30{ }^{\circ} \mathrm{C}$ in sealed tins in an atmosphere containing heptane, supplied by pipetting $50 \mu 1$ on a Whatman No. I filter paper in each Petri dish lid. After 2 days' incubation, when wild-type organisms had formed large colonies, all small colonies were picked off and those that grew on nutrient agar at the same rate as the wild-type organism were tested for growth on heptane, heptanol, heptanal and heptanoic acid by incubating in an atmosphere of the substrate as described above. To confirm that the isolates were derived from $P$. aeruginosa ATCC 17423 , the characteristic pigment formation was noted and their growth responses to phenylalanine and butan-2,3diol were tested. The wild-type organism, unlike most of the $P$. aeruginosa strains tested by Stanier, Palleroni \& Doudoroff (1966), grew on the former but not on the latter.

Preparation of cell-free extracts. A suspension of $\mathrm{I} \cdot 5 \mathrm{~g}$ (wet) bacteria in $0 . \mathrm{I}$ M-tris-chloride buffer $\mathrm{pH}_{7} \cdot 6$, total volume $6 \mathrm{ml}$, was disrupted ultrasonically, using an MSE $100 \mathrm{~W}$ ultrasonic disintegrator, for $3 \mathrm{~min}$. The extract was centrifuged at $105000 \mathrm{~g}$ for $20 \mathrm{~min}$ at $4{ }^{\circ} \mathrm{C}$ and the supernatant fluid was used for studies of enzymic heptane oxidation. In studies on the possible involvement of particulate components, this centrifugation was preceded by one at $17000 \mathrm{~g}$ for $25 \mathrm{~min}$ and followed by one at $200000 \mathrm{~g}$ for $120 \mathrm{~min}$, both at $4{ }^{\circ} \mathrm{C}$.

Assay of heptane oxidizing activity. Crude extract, containing up to Io mg protein, was added to an incubation mixture containing $70 \mu \mathrm{mol}$ tris-chloride buffer $\mathrm{pH} 7 \cdot 6,3 \mu \mathrm{mol}$ NADH and $10 \mu \mathrm{mol} \mathrm{MgCl}_{2}$ in a $25 \mathrm{ml}$ conical flask, so that the total volume was $\mathrm{I} \cdot 0 \mathrm{ml}$, and prewarmed at $30^{\circ} \mathrm{C}$ for about $3 \mathrm{~min}$. Heptane $(340 \mu \mathrm{mol})$ was then added to the flask, which was immediately stoppered and incubated with shaking at $30^{\circ} \mathrm{C}$ for $15 \mathrm{~min}$. The reaction was stopped by cooling the flask rapidly in melting ice. The products of heptane oxidation were assayed by injecting I $\mu 1$ samples of the incubation mixture into a PerkinElmer FII Mk II gas chromatograph using a glass column, $915 \times 2 \mathrm{~mm}$, packed with Porapak Q (80 to 100 mesh; Waters and Associates, Stockport, Cheshire) and operating at $230^{\circ} \mathrm{C}$. A glass capillary tube to trap non-volatile materials was used in the injection port, which was kept at $260^{\circ} \mathrm{C}$. The carrier gas, $\mathrm{N}_{2}$, flowed at $22 \mathrm{~cm}^{3} / \mathrm{min}$. Two products were detected in such assays, and had retention times identical with heptan-I-ol and heptanoic acid. The latter type predominated, typically comprising $90 \%$ of the total products. Proportionality between product concentration and recorded peak height was established for each. Heptane oxidizing activity was expressed in units (u) of $\mu \mathrm{mol}$ total products formed/min. 


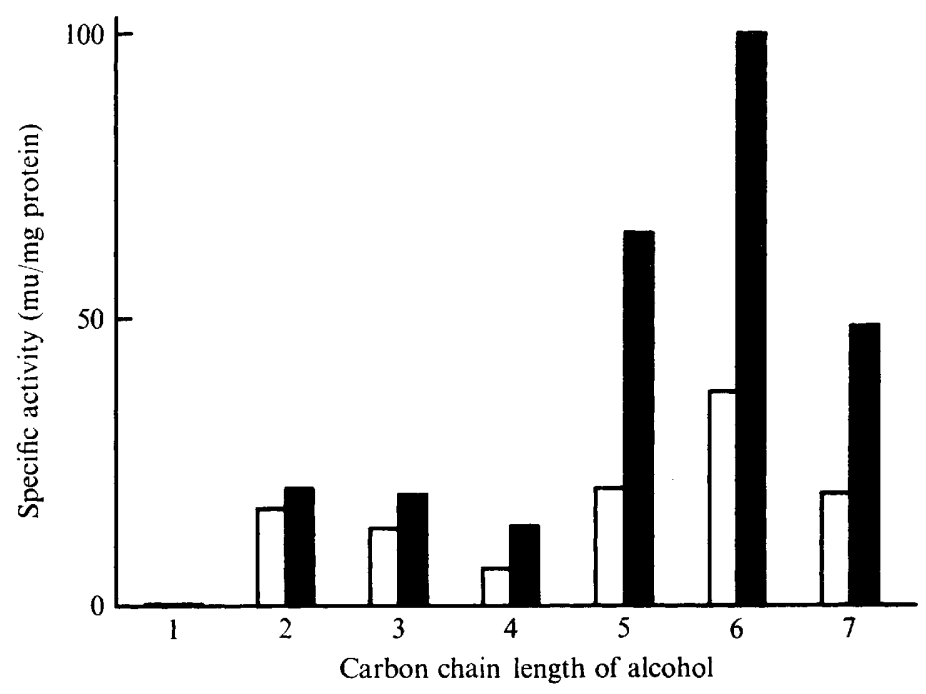

Fig. I. Alcohol dehydrogenase activities in extracts of heptane-grown and nutrient broth-grown organisms. Extracts were prepared by ultrasonic disruption and assayed for dehydrogenase activity in the presence of each alcohol from methanol to hexanol (10 mM) or heptanol (I $\mathrm{mM})$. The specific activity with each alcohol is shown for ( $\square$ ) heptane-grown and ( $\square$ ) nutrient broth-grown bacteria.

Spectrophotometric assays. Ethanol, heptanol and heptanal dehydrogenase activities were assayed at room temperature by measuring $\Delta E_{340}$ caused by the enzymic reduction of $\mathrm{NAD}^{+}$ to NADH. For ethanol and heptanol dehydrogenases, the standard reaction mixtures, in total volumes of $\mathrm{I} \cdot 0 \mathrm{ml}$, were $70 \mu \mathrm{mol}$ sodium pyrophosphate buffer $\mathrm{pH} 9 \cdot 0, \mathrm{I} \cdot 5 \mu \mathrm{mol}$ $\mathrm{NAD}^{+}$, bacterial extract, and I mmol ethanol or I $\mu \mathrm{mol}$ heptanol; for heptanal dehydrogenase they were $70 \mu \mathrm{mol}$ tris-chloride $\mathrm{pH} 8 \cdot 8, \mathrm{I} \cdot 5 \mu \mathrm{mol} \mathrm{NAD}{ }^{+}$, bacterial extract, and I $\mu \mathrm{mol}$ heptanal. Heptanol and heptanal were added as solutions in the presence of $0.05 \%$ Triton X-100, which had no effect either alone or on the ethanol dehydrogenase assay. The reactions were started by the addition of the alcohol or aldehyde substrate.

Protein estimations. Protein concentrations were estimated by a modification of the method of Lowry, Rosebrough, Farr \& Randall (I95I) described by Kennedy \& Fewson (I968).

Chemicals. DEAE-cellulose was from BioRad Laboratories, Richmond, California, U.S.A.; lysozyme, nicotinamide coenzymes and triethanolamine from Boehringer, Mannheim, Germany; diethoxymethane from Fluka AG, Buchs, Switzerland; $n$-alkanes, heptanI-ol, reduced glutathione, and $N$-methyl- $N^{\prime}$-nitro- $N$-nitrosoguanidine from Koch-Light Laboratories Ltd, Colnbrook, Buckinghamshire.

\section{RESULTS AND DISCUSSION}

The mutagenic treatment killed about $90 \%$ of the bacteria. Of approximately 25000 survivors screened, about $\mathrm{I} \%$ gave small colonies. Sixteen mutants were isolated which grew very slowly or not at all on heptane but which could still grow on heptanoic acid; all could grow on heptanol or heptanal. This corresponds to the finding that all II dodecanemutants of $P$. aeruginosa ATCC 15692 were able to grow on dodecanol or dodecanal (Macham and Heydeman, unpublished observation). Nearly all investigations have implicated the corresponding alcohol, aldehyde and fatty acid as intermediates in alkane catabolism, and 


\section{Table I. Stimulation of heptane oxidation by cations}

Metal chlorides were added, at the indicated final concentrations, to I ml crude extract $+3 \mu \mathrm{mol}$ $\mathrm{NADH}+340 \mu \mathrm{mol}$ heptane. Heptane-oxidizing activity is given relative to a value of $26.5 \mathrm{mu} / \mathrm{mg}$ protein without added cations.

$\begin{array}{lcc}\text { Cation } & \begin{array}{c}\text { Concentration } \\ (\mathrm{mM})\end{array} & \begin{array}{c}\text { Relative rate } \\ (\%)\end{array} \\ \text { None } & - & (100) \\ \mathrm{Sr}^{2+} & \text { Io } & \mathrm{I} 64 \\ & \mathrm{I} & 119 \\ \mathrm{Mg}^{2+} & \text { IO } & \text { I93 } \\ \mathrm{Ca}^{2+} & \mathrm{I} & \mathrm{II} 8 \\ & \text { IO } & 198 \\ \mathrm{Ba}^{2+} & \text { I } & 123 \\ & \text { IO } & \text { I69 } \\ & \text { I } & 15 \mathrm{I}\end{array}$

extracts of heptane-grown $P$. aeruginosa ATCC 17423 contained heptanol and heptanal dehydrogenase activities of 49 and $310 \mathrm{mu} / \mathrm{mg}$ protein, respectively. As the method of mutant selection might be expected to yield mutants defective in any of the steps in the pathway, the existence of more than one route of heptanol catabolism was considered.

Three alcohol dehydrogenases of different specificities were found in $P$. aeruginosa by van der Linden \& Huybregste (1969). To test whether $P$. aeruginosa ATCC I 7423 had more than one alcohol dehydrogenase with activity for heptanol, the dehydrogenase activity for various alcohols was measured in extracts from organisms grown on different substrates (Fig. I). Although the extract from organisms grown in nutrient broth had similar specific activities for ethanol and pentanol, that from heptane-grown organisms was more than three times as active with pentanol as with ethanol. As a single enzyme would always have the same ratio of specific activities for a given pair of alcohols, this indicates that there is in $P$. aeruginosa ATCC I 7423 more than one alcohol dehydrogenase. As no single mutation could cause the loss of all alcohol dehydrogenase activity, this is why no mutant with this deficiency was found. The heptanol dehydrogenase may itself be specified by two genes, one chromosomal and one plasmid-borne, as is octanol dehydrogenase in P. oleovorans (Chakrabarty, Chou \& Gunsalus, I973), but this was not investigated. A recent report of more than one aldehyde dehydrogenase in $P$. aeruginosa (Bertrand, Gallo \& Azoulay, 1973) suggests a similar explanation for the failure to find mutants unable to grow on heptanal.

All mutants were thus deficient in the conversion of heptane to heptanol. Suitable assay conditions for this heptane-oxidizing system were established, using extracts of the wild type. The total amount of products formed was proportional to time over the first $15 \mathrm{~min}$ and proportional to extract concentration up to $9 \mathrm{mg}$ protein/assay $(3.5 \mu \mathrm{mol}$ products/ I 5 min). Aeration was essential for heptane oxidation, and the addition of NAD ${ }^{+}, \mathrm{NADPH}$ or, especially, NADH, increased the rate. Activity was independent of the amount of heptane added between 68 and $1360 \mu$ mol. Of buffers tested, tris- $\mathrm{HCl}$ and triethanolamine- $\mathrm{HCl}$ gave the greatest activity. Maximum activity of from 20 to $30 \mathrm{mu} / \mathrm{mg}$ protein was observed at $\mathrm{pH} 7 \cdot 6$; activity was at least $90 \%$ of the maximum within the range $\mathrm{pH} 7 \cdot 0$ to $7 \cdot 8$. Of the metal chlorides tested, only $\mathrm{Sr}^{2+}, \mathrm{Mg}^{2+}, \mathrm{Ca}^{2+}$ or $\mathrm{Ba}^{2+}$ stimulated activity (Table I). Extracts dialysed at $3{ }^{\circ} \mathrm{C}$ for $4 \mathrm{~h}$ against 500 vol. of $0 \cdot \mathrm{I}$ M-tris- $\mathrm{HCl}, \mathrm{pH} 7 \cdot 6$, lost all heptane-oxidizing activity but it was restored by adding Io $\mathrm{mm}-\mathrm{MgCl}_{2}$ to the assay mixture; this addition was therefore routinely made to ensure that full activity was expressed in the assays. Stimulation 


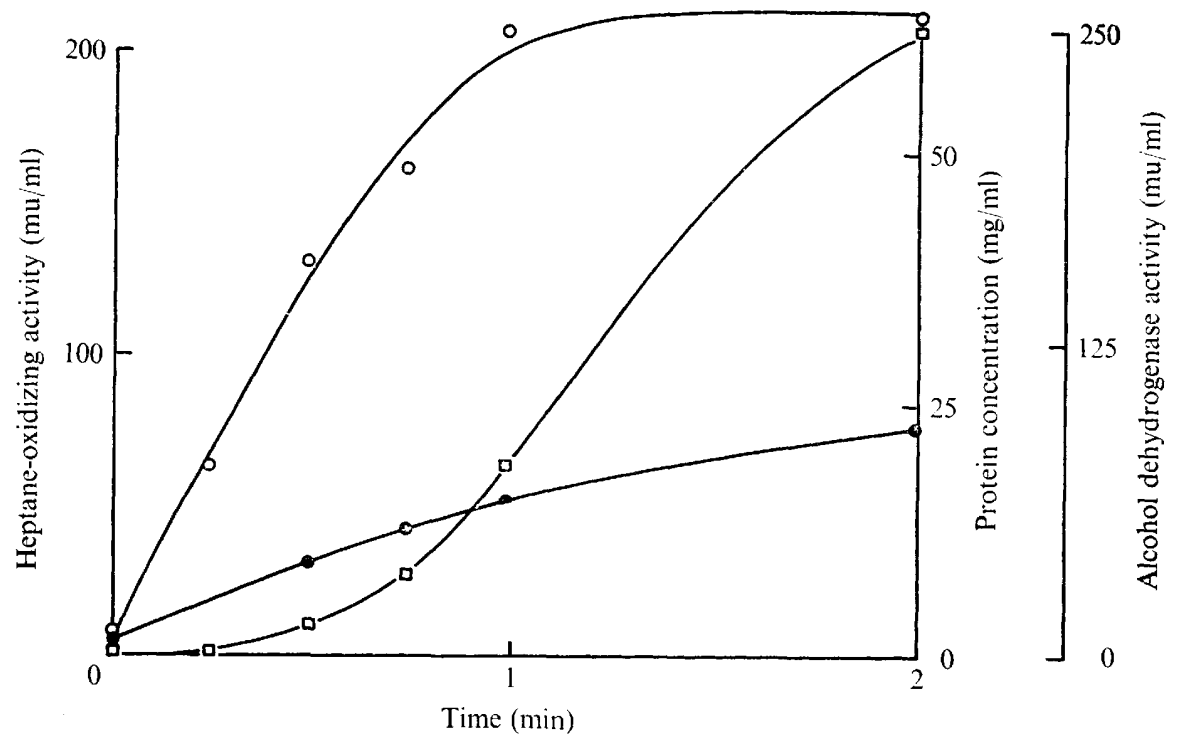

Fig. 2. Release of heptane-oxidizing activity during ultrasonic disruption. Samples were removed from a suspension of $P$. aeruginosa ATCC 17423 after different times of ultrasonic treatment, and centrifuged. The supernatant fluids were assayed for heptane-oxidizing activity ( $\square$ ), alcohol dehydrogenase activity $(\bigcirc)$ and protein $(\bullet)$. For methods, see text.

by, but not absolute dependence on, $\mathrm{Mg}^{2+}$ was reported by van Eyk \& Bartels (1970); they did not investigate the effects of other group IIA cations.

Heptane-oxidizing activity was unaffected by $25 \%$ carbon monoxide in the gas phase of the assay system, thereby substantially discounting the involvement of cytochrome P-450 in the system, in common with other pseudomonad alkane-oxidizing systems (Peterson, Basu \& Coon, 1966). The heptane-oxidizing activity of extracts diminished rapidly when they were stored; typically about $85 \%$ was lost in $20 \mathrm{~h}$ at $3{ }^{\circ} \mathrm{C}$. Of the thiol reagents tested, only thioglycollate, at $2 \mathrm{~mm}$, preserved activity during storage; dithiothreitol, glutathione, L-cysteine and 2-mercaptoethanol were ineffective. Van Eyk \& Bartels (1970) were unable to protect the alkane hydroxylase activity in extracts of $P$. aeruginosa ATCC 473 using thiol reagents, but thioglycollate was not tested by them.

During a study of the optimal conditions for preparation of the cell-free extract, two procedures yielded results indicating that the heptane oxidation system, or part of it, could be particulate or membrane-bound. During ultrasonic disruption, the release of the heptaneoxidizing system into the supernatant fluid was subject to a lag (Fig. 2), although total protein and ethanol dehydrogenase activity were released without a lag. This suggested that a component requiring more extensive disruption was necessary for heptane-oxidizing activity. That the system comprised more than one component was shown when a partial separation of activity was achieved after centrifuging at $200000 \mathrm{~g}$ for $\mathrm{I} 20 \mathrm{~min}$, when the supernatant fluid lost about $65 \%$ of activity but only about $35 \%$ of the protein (Table 2). The pellet, though itself inactive, restored most of the lost activity to the supernatant fraction when recombined with it. As full activity was not restored it may be that the prolonged centrifugation partially inactivated a component of the system. The residual activity in the supernatant fraction suggested that the sedimented component was either not essential or only incompletely removed. 
Table 2. Effect of centrifuging on the heptane-oxidizing system

A crude extract prepared by ultrasonic disruption of $P$. aeruginosa ATCC 17423 was centrifuged at $17000 \mathrm{~g}$ for $25 \mathrm{~min}$. The supernatant fluid was treated and the heptane-oxidizing system assayed in the fractions as summarized in the Table.

Centrifugation procedure summary

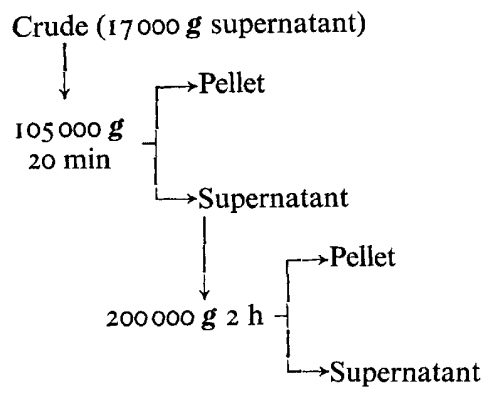

\section{Heptane-oxidizing activity $(\mathrm{mu} / \mathrm{ml})$}

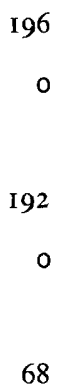

Heptane-oxidizing system specific activity (mu/mg)

Activity after remixing $(\mathrm{mu} / \mathrm{ml})$

Table 3. Heptane oxidation by mixed extracts

Extracts were prepared and assayed for activity as described in Methods, but using mixtures of equal amounts of two extracts. When the activity of the mixture exceeded the sum of the activities of the two extracts assayed separately by $80 \%$ or more, the result was scored + ; otherwise 0 . $\mathrm{A}, \mathrm{B}, \mathrm{C}$ and $\mathrm{D}$ are mutant groups, and the numbers are mutant numbers.

\begin{tabular}{|c|c|c|c|c|c|c|c|c|c|c|c|c|}
\hline & & & & & B & & C & & & D & & \\
\hline & I5 & 26 & 66 & 80 & 9I & 6I & II 5 & 129 & 8 & I I & 23 & type \\
\hline I5 & & 0 & 0 & 0 & + & 0 & 0 & 0 & 0 & 0 & + & 0 \\
\hline 26 & & & 0 & 0 & + & 0 & 0 & 0 & + & + & + & + \\
\hline 66 & & & & 0 & + & 0 & 0 & 0 & + & + & + & + \\
\hline 80 & & & & & + & 0 & 0 & 0 & + & + & + & + \\
\hline 9I & & & & & & 0 & 0 & 0 & + & + & + & 0 \\
\hline 6I & & & & & & & 0 & 0 & 0 & 0 & + & 0 \\
\hline II 5 & & & & & & & & 0 & 0 & 0 & + & 0 \\
\hline 129 & & & & & & & & & 0 & 0 & 0 & 0 \\
\hline 8 & & & & & & & & & & + & + & 0 \\
\hline I I & & & & & & & & & & & + & 0 \\
\hline 23 & & & & & & & & & & & & \\
\hline
\end{tabular}

The assay system, standardized as for wild-type extracts, was used to investigate extracts of the mutants. Extracts were prepared from bacteria grown on malonate with diethoxymethane. Of the sixteen mutants, two had high reversion rates, two, which may be permeability mutants, grew slowly on heptane but had heptane-oxidizing activity approaching that of the wild type, and one did not grow on malonate; these were not further investigated. Three mutants, 8, I I and 23, grew very slowly on heptane and had variable, but little, heptaneoxidizing activity, never exceeding $25 \%$ that of the wild type. No other mutant had detectable heptane-oxidizing activity.

Samples of extracts from each mutant were assayed together with extract from each other mutant in turn (Table 3) or with extract from the wild type. The extracts complemented each other in some mixtures: the activity of the mixture exceeded the sum of the activities of the two extracts separately. Although the activity in many of the mixings varied from one batch of organisms to another, the presence or absence of complementation was consistent. 
From the complementation pattern, the mutants may be resolved into four groups. Group A comprised mutants 26, 66 and 80 which were the only ones which significantly stimulated the wild-type extract, and, when mixed with extract from mutant 9I, generated heptane-oxidizing activity about equal to that of wild-type extract. Mutant I 5 also complemented 9I, although the activity produced was very low, and was also included in group A. Group B mutant 9I was unique in possessing no heptane-oxidizing activity and complementing extracts of group A.

Mutants 6I, I I 5 and I 29 were classified together as group $C$ : they were unable to stimulate wild-type extract activity, and did not complement extracts from either group A or group B. Only two positive interactions resulted from all mixing experiments involving group C: 6 I plus 23 , and II 5 plus 23 . Some of the mutants in group $\mathrm{C}$ may lack activity because the inducer failed to enter the organisms, or, having entered, failed to induce the enzymes.

Mutants 8, I I and 23, which possessed residual activity when assayed individually, yielded complex complementation results. In general, they interacted with both groups A and B, but not with $\mathrm{C}$. They were therefore classed as group D. For all mutant extracts the ability to complement other extracts in mixing assays was destroyed by prior heat treatment at $80^{\circ} \mathrm{C}$ for $20 \mathrm{~min}$.

The factors $F_{A}$ and $F_{B}$, addition of which produced activity in group $A$ and group $B$ extracts respectively, were partially purified. Assay of the factors was made possible by finding that the activity of mixtures of $\mathrm{A}$ and $\mathrm{B}$ extracts was proportional to the concentration of either extract when tested with an excess of the other. $F_{A}$ was fractionated from type $B$ extracts by ammonium sulphate treatment. Although a third of $F_{A}$ activity was lost, about $90 \%$ of the remainder precipitated between 25 and $35 \%$ saturation. Investigations of wildtype extracts had suggested that a component of the heptane-oxidizing system might be located in the membrane fraction but attempts to separate the system's components by lysis of wild-type organisms, using EDTA and lysozyme, resulted in almost total loss of heptane-oxidizing activity. When the type-B mutant was lysed by the same method and the particulate fraction collected, it contained considerable $F_{A}$ activity. In contrast, studies on $F_{B}$ were restricted by its lability. Nearly all activity was lost during overnight storage and also during ammonium sulphate fractionation. When type-A mutant extract was mixed with DEAE cellulose in the presence of $20 \mathrm{mM}$-tris-chloride buffer $\mathrm{pH} 7.4$, all $F_{B}$ was removed from solution. About $40 \%$ of the $F_{B}$ was then eluted from the DEAE cellulose with 300 mM-buffer. The recovery of additional $F_{B}$ by elution at higher buffer concentrations was difficult to assess because such concentrations were found to be inhibitory in the assay system. Conventional column chromatography took so long that most of the $F_{B}$ activity was lost.

The heptane-oxidizing system of $P$. aeruginosa ATCC 17423 thus possessed at least two components, membrane-bound $F_{A}$ and labile $F_{B}$. The pseudomonad alkane-oxidizing systems studied by Peterson, Kusunose, Kusunose \& Coon (1967) and by van Eyk \& Bartels (1970) have each been shown to comprise three components: a membrane-bound hydroxylase, a very labile NADH-rubredoxin reductase and rubredoxin. In view of the similarities between the known properties of the $P$. aeruginosa ATCC 17423 heptane-oxidizing system and these other systems, it was thought possible that a third, probably rubredoxin-type, component could be involved, and that a lack of it might be the defect in group D mutants. Were this so, then if both group A and group B extracts contained this rubredoxin, the observed stimulation of group D mutants by them would be accounted for. This hypothesis was discounted, however, when it was found that ammonium sulphate treatment of group A extracts greatly diminished their ability to stimulate group D extracts. Residual activity 
was in the $F_{B}$ fraction. In view of the known stability of rubredoxin-type proteins to ammonium sulphate fractionation, the factor in group A extracts which stimulated group D extracts was probably the same factor that complemented group B extract, and not a rubredoxin. Group D mutants were therefore probably partially defective with respect to both $F_{A}$ and $F_{B}$, perhaps because of a defect in the induction transcription system for the relevant operon. Attempts to show the involvement of a third factor by purification of $F_{A}$ and $F_{B}$ were unsuccessful: further purification of $F_{B}$ beyond DEAE adsorption treatment was restricted by its lability, and when $F_{B}$ partially purified to this stage was combined with ammonium sulphate-fractionated $F_{A}$, heptane-oxidizing activity was still present.

Although no direct evidence for a third component was found, its involvement could not be excluded. The results of the complementation experiments cannot readily be explained in terms of a two-component system. The failure to isolate mutants lacking rubredoxin may have been due to the small total number of mutants selected. Alternatively, rubredoxin may fulfil another, unknown, metabolic function so vital that a rubredoxin-deficient mutant could not live.

\section{REFERENCES}

Baptist, J. N., GHolson, R. K. \& CoON, M. J. (1963). Hydrocarbon oxidation by a bacterial enzyme system. I. Products of octane oxidation. Biochimica et biophysica acta 69, 40-47.

Bertrand, J. C., Gallo, M. \& Azoulay, E. (1973). Aldéhyde déshydrogénases soluble et particulaire de Pseudomonas aeruginosa. Biochimie 55, 343-350.

Chakrabarty, A. M., Chou, G. \& Gunsalus, I. C. (1973). Genetic regulation of octane dissimilation plasmid in Pseudomonas. Proceedings of the National Academy of Sciences of the United States of America 7o, II $37-1140$.

van EyK, J. \& Bartels, T. J. (1968). Paraffin oxidation in Pseudomonas aeruginosa. I. Induction of paraffin oxidation. Journal of Bacteriology 96, 706-7I 2.

van Eyk, J. \& BARTels, T. J. (1970). Paraffin oxidation in Pseudomonas aeruginosa. II. Gross fractionation of the enzyme system into soluble and particulate components. Journal of Bacteriology 104, 1065-1073.

GHolson, R. K., BAPtist, J. N. \& CoON, M. J. (I963). Hydrocarbon oxidation by a bacterial enzyme system. II. Cofactor requirements for octanol formation from octane. Biochemistry 2, I I55-I I 59.

ILLARIONOV, E. F. (1972). A study of the intermediate stages of biochemical oxidation of higher $n$-alkanes by paraffin-negative mutants of Pseudomonas denitrificans. Mikrobiologiya 4r, I26-131.

Jenkins, P. G., Raboin, D. \& Moran, F. (I972). Mutants of Mycobacterium rhodochrous with modified patterns of $n$-paraffin utilization. Journal of General Microbiology 72, 395-398.

KenNedy, S. I. T. \& Fewson, C. A. (1968). Enzymes of the mandelate pathway in bacterium NCIB8250. Biochemical Journal 107, 497-506.

Kusunose, M., Ichihara, K., Kusunose, E., Nozaka, J. \& Matsumoto, J. (1967). The possible role of flavine in the hydroxylation of hydrocarbons by bacterial enzyme systems. Agricultural and Biological Chemistry 31, 990-992.

van Der Linden, A. C. \& HuYbregste, R. (1969). Occurrence of inducible and NAD(P) independent primary alcohol dehydrogenases in an alkane-oxidizing Pseudomonas. Antonie van Leeuwenhoek 35, 344-360.

Lowry, O. H., Rosebrough, N. J., Farr, A. L. \& Randall, R. J. (1951). Protein measurement with the Folin phenol reagent. Journal of Biological Chemistry 193, 265-275.

Peterson, J. A., Basu, D. \& Coon, M. J. (I966). Enzymatic $\omega$-oxidation. I. Electron carriers in fatty acid and hydrocarbon hydroxylation. Journal of Biological Chemistry 24I, $5162-5164$.

Peterson, J. A., Kusunose, M., Kusunose, E. \& Coon, M. J. (1967). Enzymatic $\omega$-oxidation. II. Function of rubredoxin as the electron carrier in $\omega$-hydroxylation. Journal of Biological Chemistry 242, 4334-4340.

Stanier, R. Y., Palleroni, N. J. \& Doudoroff, M. (I966). The aerobic pseudomonads: a taxonomic study. Journal of General Microbiology 43, 159-27I. 